\title{
Immigrant Settlement Services Literacy
}

\author{
Mambo Tabu Masinda \\ Burnaby School District, Canada \\ E-mail: mambo_masinda@yahoo.ca
}

Received: March 21, 2014 Accepted: July 17, 2014 Published: December 25, 2014

doi: $10.5296 /$ ijsw.v1i2.5335

URL: http://dx.doi.org/10.5296/ijsw.v1i2.5335

\begin{abstract}
The global migration is transforming the social fabric of modern societies around the world. As a result, countries hosting large number of immigrants have developed a range of services to help immigrants adjust to their new countries. Many studies have investigated immigrant services, however, there is no discussion looking at immigrant services under what I call "Immigrant settlement services literacy" (ISSL). This paper aims to close this gap. The discussion proposes some implications for immigrant settlement services planning, delivery and evaluation in light of the notion of immigrant services literacy.
\end{abstract}

Keywords: Immigrant settlement service literacy - immigrants - literacy, integration services

\section{Introduction}

Trends in global migration indicate that many countries around the world are progressively becoming multicultural and ethnically diverse when taking into consideration the complex fabric of culture, race, religion and ethnicity of immigrants. In this context, a mounting sector of services designed to assist increasing numbers of immigrants and refugees integrate into their new societies has grown to become a vital part of government policies and communities in countries such as Canada, USA, UK, France, Australia and New Zealand. However, I argue that the availability of immigrant settlement services (ISS) may not be sufficient by itself if immigrants do not have the appropriate skills and aptitudes to fully benefit ISS. Just as a computer is useless without the skills to use it, so are ISS worthless if immigrants are unable to competently access and critically use them.

With this concern in mind, the following question arises: What does it take for immigrants to fully access, effectively use and keep ISS on the political agenda in order to individually and collectively integrate into their new society? The same way researchers and practitioners have devoted time and energy to understanding the relationships between literacy and health, 


\section{N Macrothink}

International Journal of Social Work

ISSN 2332-7278

2014, Vol. 1, No. 2

technology, and media, to name a few; I am discussing here the relationship between ISS and literacy. My objective is to present what I call "immigrant settlement services literacy" (ISSL) and show how important this discussion is to better plan, deliver and evaluate ISS.

In reality, although there is a sincere dedication to understand ISS in countries receiving large number of immigrants, to my knowledge there is no study that discusses the concept of ISS literacy. I draw the concept of ISSL from existing thoughts on different types of literacy such as information literacy, cultural literacy, media literacy, computer literacy and health literacy. The objective here is to link ISSL to policy development, implementation of appropriate policy responses to knowledge, access, and effective use of ISS, as well as to the political mobilization of ethnic groups. The following discussion suggests some implications for the planning, delivery and evaluation of services.

I begin with a brief literature review of the main concepts used in the paper, namely "services", "settlement services", and "literacy" in order to help the reader understand the linkage I am drawing between ISS and literacy. In the next section, I present the idea of "immigrant settlement services literacy", its definition and measures. The following segment draws attention to some factors that enable the use of ISS while the final section presents some implications ISSL may have for ISS planning, delivery and evaluation.

\section{Defining Services, Settlement Services and Literacy}

Without getting into a debate on what services are, they tend to be considered intangible activities, contrasted with production. They include, for example, repairs and marketing, and may be grouped into economic and social or human services. In addition, even though there is no unanimity on the definition of social or human services, I agree with the human services definition provided by Martin, (2007) in his book titled Introduction to human services: Through the eyes of practice settings. She claims that human services are supportive, developmental or enlightening services provided to the community, which are designed to enhance the quality of life and well-being of citizens and communities. This definition of human service aligns with the one provided by the Merriam-Webster Online Dictionary, which considers a service as an activity designed to promote social well-being. With the above definitions in mind, we consider ISS to be social or human services which promote the social well-being of immigrants and contribute to their full integration in their new countries.

In a 1984 report, B. Saddeiqa Holder stated that "settlement services refer to services provided to immigrants and refugees upon their arrival to facilitate their reception and settlement in a new country" (Cited by COSTI, 2001). It has become evident to most policymakers, scholars and immigrant service providers that access to and efficient use of ISS is key to immigrants' successful integration in their new society. Yet, ISS are becoming extremely complex. This complexity complicates the access and use of immigrant services.

For example, there are differences in what is available for immigrant services for skilled workers, temporary workers, government and private sponsored refugees and policies which determine eligibility can change any time. In addition, due to a variety of factors ranging from language skills, culture and gender, length of stay in the country, level of education, 
country of origin, and so forth, navigating immigrant services is not an easy task. This leads to the importance of literacy in relation to ISS because it is vital to individual and community develop competencies to effectively, critically use and keep immigrant services on the political agenda.

Let us now figure out what immigrant settlement and integration mean. According to COSTI (2001), the idea of ISS is often used together with the word "integration" which relies on the classical definition of immigrants integration provided by the United Nations Economic and Social Council, as a gradual process by which new residents become active participants in the economic, social, civic, cultural and spiritual affairs of a new homeland. This definition has been adopted by many national, provincial and local organizations. For example, it fits with the Canadian Council of Refugees' (1998) definition, as well as that of the Ontario Coalition of Agencies Serving Immigrants (OCASI). The latter defines immigrant integration as "a long-term, dynamic, two-way process through which, ideally, immigrants would achieve full equality and freedom of participation in society, and society would gain access to the full human resource potential in its immigrant communities" (Cited by COSTI, 2001).

Literacy is one of the difficult concepts to define as it has different meanings in different contexts. This paper does not intend to engage in a debate around its different meanings. However, it can be said without dispute that the definition of literacy has evolved from a narrow perspective to a much broader one. In fact, the concept of literacy has progressed from referring simply to the straightforward capacity to read, to comprising different levels and a plurality of literacies (Sørensen, Van den Broucke, Fullam et al., 2012). For social theorists, literacy was first associated with social and economic development. After that, the definition was expanded beyond the knowledge of basic technical skills, a narrow view focusing on increasing individual productivity to a much broader approach which argues that literacy must empower individuals and communities in a plurality of domains (UNESCO, 1965), such as immigrant services.

For example, Freire (1972) drew attention to the political dimensions of literacy, calling for the teaching of literacy through cultural actions relevant to the learner and, more significantly, as the method of "conscientization". According to Freire (1972) point of view, literacy should give the learner the confidence to question why things are the way they are, and to undertake the challenge of changing them for the better. This approach suggests that immigrants should be enough empowered to politically participate in ISS planning, delivery and evaluation. Since the 1970s, a number of literacy pillars have been introduced to centre learning needs around learning to know to do, to live together and to be (Delors et al., 1996).

In summary, the evolution of the construct of literacy has led to an understanding of literacy that goes beyond the mere reading and writing skills to incorporate social practices contributing to the broader outcomes of lifelong learning which incorporates a critical approach of literacy. In the context of services provided to immigrants, ISSL should transform the immigrant from being an object passively receiving services to an agent of change of his/her live conditions (Perry, 2012). 


\section{What Enables the Knowledge, Access and Use of ISS?}

It has been argued that human willingness to seek assistance from others is a basic and universal human disposition (Fisher, Durrance, \& Hinton, 2004). This implies that as soon as people move to a new country, they quickly start to inquire about available services that may help them settle and feel at home. Indeed, after arriving in a new country, newcomers establish new patterns of information seeking and develop new information sources (Mehra, \& Papajohn, 2007). Unfortunately, research on immigrants has overwhelmingly focused on some aspects of their settlement such as earnings, employment, schooling issues (De Jong et al., 2002) with little academic attention paid to understanding the developmental process of skills which are needed to be a literate in immigrant settlement services.

Fisher, Durrance, \& Hinton (2004) acknowledged that human services seeking behavior is influenced by individuals' environmental settings. In this case, it may be said that immigrants' socioeconomic status, knowledge of information sources and channels, availability and accessibility of services, level of education, culture, gender, length of stay in the new country, influence immigrants' services seeking patterns and their capacity to politically act on ISS issues. Further, the perceptions immigrants may have on their capacity or inability to influence how services are delivered may also affect their desire and willingness to seek for help. Similarly, since human beings are social animals, the capacity to better use ISS is also influenced by the structure of one's social networks, in other terms ISSL depends to a large extent on the size and reliability of someone's network of friends, family members.

Because the concept of information seeking is closely related to ISS seeking, some studies have started to explore immigrants' information seeking behavior defined as "how people need, seek, give, and use information in different contexts" (Pettigrew, Fidel, \& Bruce, 2001, p. 44). For example, Silvio (2006) looked at the information needs of Southern Sudanese immigrant youth in the city of London, Canada and findings showed that the youths' chief sources of information included colleagues, friends, neighbors and relatives. The results also showed that respondents tended to seek information that was easily accessible, preferably from interpersonal sources, unless there was a particular reason for avoiding them.

Analyzing the information behavior of migrant Hispanic farm workers and their families in the Pacific Northwest USA, Fisher, Durrance, \& Hinton (2004) noted that language, culture and economics were identified as the greatest obstacles to information seeking. Education wise, Gross (2005) investigated the links between low levels of education and information seeking. He discovered that low-level information seeking skills affects individuals' abilities to recognize not only the need for specific information, but also the capacity to use and effectively navigate the information system.

On another note, Liu (1995) established that language and trust are important factors in selecting information sources for immigrants. In the same perspective, it has been consistently reported that immigrants prefer to seek information from other immigrants (Silvio, 2006). It has also been said that unsuccessful information seeking practices may foster or inhibit civic engagement because immigrants may feel alienated and not part of their 
communities (Dechief, 2006).

An interesting report titled Literacy for life: Further results from the Aadult Literacy and Life Skills Survey conducted by Statistics Canada \& OECD (2010), provided fascinating commentary on immigrants' level of literacy in Canada. The report showed that in Canada there are higher proportions of immigrants at both the high and low ends of the literacy scale than of those who are Canadian born. In addition, immigrants with a first language other than English have significantly lower literacy rates than other Canadians, with $60 \%$ below level 3 of literacy. Significantly, this proportion does not improve with time in Canada. This finding has many implications for immigrants' capacities to navigate ISS.

\section{Immigrant Settlement Services Literacy Definition and Its Indicators}

\subsection{In Search of a Definition}

Considerable time and resources have been dedicated to developing better understandings of ISS in countries receiving large number of immigrants. However, no study exists that has looked at ISS literacy. This discussion drives from Nutbeam's (2000) description of the three levels of health literacy: 1) functional health literacy, 2) interactive health literacy and 3) critical health literacy. In his analysis of critical health literacy, Nutbeam (2000) elaborated on the communication of information, and the development of skills which help appreciate the political feasibility and organizational possibilities of various forms of action to address social, economic and environmental determinants of health. This guided my thoughts on ISSL.

I define ISSL as an ongoing process of competencies enrichment enabling immigrants to know, understand, access, critically navigate immigrant services and gain political skills to effectively mobilize the mainstream society so that immigrant services are part of the political agenda. It consists of three developmental stages: 1) learning about, navigating and appropriate use of ISS, 2) gaining critical knowledge of ISS and 3) attaining demonstrating political mobilization skills for suitable ISS.

Boekhorst (2003) reminds us that information literacy should be thought of as a process consisting of the recognition of the need for specific information; the retrieval of that information and its use to acquire further knowledge; and evaluation of the information acquired. Similarly, ISSL is an iterative and recurrent processes in which immigrants know the available services corresponding to their needs; learn and gain skills that help them understand that ISS exist for them, learn how to use them, critically identify strengths and gaps in services, and finally become skilled at political mobilization aimed at addressing the gaps in ISS.

Looking at ISSL as a lifelong process, ISSL consists of three levels: 1) basic immigrant settlement service literacy (BISSL), 2) critical immigrant settlement service literacy (CISSL), and 3) Political Immigrant Settlement Service Literacy (PISSL). At the Basic Immigrant Settlement Service Literacy (BISSL) level, immigrants are trained to acquire the basic skills about the existing services, how to use and get access, and navigate ISS. Different outreach tools such as immigrant resource guides, internet, television, brochures, word of mouth, 
friends and family members are used at this point to let individuals and communities know about available services. At this level of ISSL, different methods of knowledge transfer are required to take into account the diversity of individuals and communities. Keep in mind that at each stage of ISSL development, different factors may play a critical role as either catalyst or barrier. These could include culture, language, self-confidence, level of education, and the size and resources of existing community networks.

Without locking developmental levels into silos, during the basic immigrant settlement service literacy individuals and communities acquire an integrated sense of the mapping of existing service. Once this is developed, individuals and communities should focus on developing critical thinking skills about immigrant services quality, appropriateness, strengths and gaps. This developmental stage is the Critical Immigrant Settlement Service Literacy (CISSL). In practice, ISS providers should set up the resources aiming to train immigrants and ethnic communities about the rights to have their voice heard regarding immigrant services; teach them suitable ways of approving or disagreeing with the way services are planned, delivered and evaluated and help immigrants develop skills to request their participation to searching potential solutions in addressing the gaps in ISS.

As immigrants and communities develop their abilities to navigate ISS, some may avoid asking for help even existing services do not provide appropriate assistance because they think this is not a right or feel powerless in their capacity to change existing conditions. However, it is possible that individuals with high ISSL will start questioning the way organizations plan and deliver services and, in doing so, raise their voices to call for improvements in services. Immigrants with high ISSL may want to be consulted in the process of hiring culturally competent workers who will better understand their needs; ask policymakers to be consulted about planning services for them and be part of advisory bodies in charge of conducting immigrant services evaluation.

At the Political Immigrant Settlement Service Literacy (PISSL) level, individuals and ethnic communities are aware of their capacities to not only question, but also change the course of immigrant services policy. They begin to organize themselves as agents of change for their own benefit and their communities. At this stage, some immigrant services providers should focus on promoting immigrant political involvement with the objective to engage immigrant leaders in mainstream organization pushing policymakers to bring ISS on the government political agenda. In addition, ethnic community leaders may strategically decide to join political parties sensitive to the need of immigrant communities at different levels of government. Indeed, for immigrant effective participation in political mobilization, leadership skills development is crucial and immigrants with relevant firsthand skills and experience in various domains from within immigrant communities may play a critical role in developing PISSL.

\section{Identifying ISSL Indicators}

How do we measure ISSL is an important question to be answered? To begin responding to this question, there is a need of identifying indicators that can better monitor progress at different stages of ISSL. However, designing indicators is always a difficult task because the 


\section{Macrothink}

International Journal of Social Work

ISSN $2332-7278$

2014, Vol. 1, No. 2

definition of what is being measured may differ among policymakers, services providers and immigrant themselves. The following tables suggest some possible ISSL indicators. The first column in table 1 describes the three levels of ISSL: basic, critical and political. At each level, there are specific indicators. For example, being able to read and understand written immigrant resources about existing immigrant services, using the internet to access services, effectively use the social networks of friends, and the ability to navigate ISS, are some indicators for BISSL.

CISSL can be measured by looking at individuals and community aptitudes to evaluate the quality, appropriateness, strengths and gaps in immigrant services provided to them. For example, immigrants should be able to ascertain whether available services are making a difference in their human progress, and reflect on what may be missing to ensure that the full continuum of services is in place for their full integration into their new homeland. Another measure could be the level of readiness among immigrants to suggest new ways or potential solutions for better services. At this point, the capacity of individuals and communities to question organizations services delivering services could be translated into community leaders meeting with NGO representatives to ask for improvements in service planning, delivery and evaluation. One commonly heard request is for culturally sensitive workers who will better understand their needs.

I believe that the PISSL is the most sophisticated literacy and very difficult to reach. In fact, not only individuals should be aware of their capacity to effect change, but more importantly, the community has to attain a community consciousness of their capacity to change the course of their lives. It takes individuals and communities as a whole to see themselves as agents of change. At this stage, ethnic community leaders feel they have the potential to influence their integration by acting consciously on the political agenda in their constituency. For this to happen, specific immigrant communities may have accumulated enough economic power and acquired community mobilization and leadership skills which influence political parties to be sensitive to their community's concerns at different levels of government. 
Table 1. Immigrant settlement services literacy indicators (ISSL)

\section{Level of ISSL Indicators}

\section{Basic ISSL}

\begin{tabular}{ll}
\hline & $\begin{array}{l}\text { Read and understand immigrant resource guides } \\
\text { Know to use the internet to learn about immigrant services }\end{array}$ \\
$\begin{array}{l}\text { Individuals and communities } \\
\text { have the skills enabling } \\
\text { navigation, knowledge, and } \\
\text { use of ISS }\end{array}$ & $\begin{array}{l}\text { Connected to friends from own and other communities } \\
\text { Know the locations of ISS } \\
\text { Know the illegibility criterion of ISS } \\
\text { Know what to do to access ISS }\end{array}$ \\
\hline
\end{tabular}

\section{Critical ISSL}

Individuals and communities have an integrated sense of existing services and critically think about service quality, appropriateness, strengths and gaps
Capable to suggest potential solutions for better immigrant services

Critically think about service appropriateness, strengths and gaps

Familiar with immigrants rights to appropriate services

Capacity to question organizations about service planning, delivery and evaluation

\section{Political ISSL}

Individuals and ethnic communities are aware of their individual and collective capacities to not only question but also change the course of their integration
Perceive community organizations as agents of change

Ethnic communities' awareness to influence policy about immigrant services

Ethnic community leaders are involved in political parties at different levels of government (federal, provincial and municipal)

Community leaders seat on different advisory team of immigrant services

Number of professionals in various domains of mutuality, civic, and community-based politics.

Table 2 suggests how to possibly analyze individual levels of ISSL using a 5 point scale from $1=$ very poor, $2=$ poor, $3=$ fair, $4=$ very good, to $5=$ excellent. In order to assess their global ISSL, individuals complete the questionnaire and total the number of responses for each type of ISSL. The results are measured as follows: 5) Excellent ISSL scores between 121 and 150,4) Very Good ISSL scores between 91 and 120, 3) Fair ISSL scores between 61 and 90,2) Poor ISSL scores between 31 and 60 and, 1) Very Poor ISSL scores between 1 and 30. It is our understanding that within each level of ISSL individuals or communities may be at different stages. 


\section{Macrothink}

Table 2. Tracking level of ISSL

\begin{tabular}{|c|c|c|c|c|c|c|}
\hline & Items & 1 & 2 & 3 & 4 & 5 \\
\hline 1 & My income allows me to make it to the end of the month & & & & & \\
\hline 2 & My culture is distant from that of Canadians & & & & & \\
\hline 3 & I know about ISS and where they are located & & & & & \\
\hline 4 & I read and understand immigrant resource guides & & & & & \\
\hline 5 & I use the internet & & & & & \\
\hline 6 & I know the location of specific programs for immigrants & & & & & \\
\hline 7 & I know the eligibility criteria for various ISS & & & & & \\
\hline 8 & I can use the internet to look for ISS & & & & & \\
\hline 9 & I can read and understand printed ISS material & & & & & \\
\hline 10 & I use the instructions given to me by ISS providers & & & & & \\
\hline
\end{tabular}

\section{Total (1)}

1 I know where to find culturally sensitive ISS

2 I know which ISS are or are not relevant for me

3 I have a sense that ISS providers listen to me

4 I know how to seek for help

5 I communicate with ISS providers

6 I am aware of the gaps in ISS

7 I can change the course of the way ISS are provided

8 I can influence policy around ISS

9 I have the capacity to question ISS agencies

10 I'm thinking about getting involved in politics to change ISS policy

\section{Total (2)}

1 I can change policy around ISS issues

2 I can influence policy around ISS

3 My community can change ISS policy

4 I am involved in political parties that support ISS

5 My community is organized as an agent of change

6 Community leaders participate in political parties

7 Ethnic community leaders are aware of their strengths

8 Ethnic community leaders have political skills

9 Community professionals are involved in political mobilization

10 I am involved in politics to change ISS policy

Total (3) 


\section{Implications for ISS Planning, Delivery, Evaluation and Policy}

As described above, ISSL is a process ranging from 1) learning about, navigating and using ISS, 2) gaining critical knowledge of ISS to 3) achieving political mobilization skills for keeping ISS on the political agenda. From their arrival in their new country throughout their life course, immigrants will continually develop skills around ISS available to them. An immigrant settlement services literate is then an immigrant who is able to fully understanding, critically identify the gaps and contribute in keeping immigrant settlement services at the centre of the political agenda. More importantly, the immigrant settlement services literacy must be looked at the societal level influencing immigrants' ISSL.

The discussion suggest that research on immigrants' services should expand its focus beyond the traditional domain of services availability and delivery to include developing immigrants' abilities to critically use and think about ISS, as well as promoting political skills to ensure their concerns are on the mainstream political agenda. This approach may generate potential new patterns of planning, delivering and evaluation of ISS.

For example, in terms of ISS planning, the bureaucratic approach consisting of designing projects with little consultation of ethnic communities must be questioned. In fact, many of services in place fail to meet the actual needs of targeted communities simply because the later were not consulted during the planning process. As an alternative, ISS planners should incorporate immigrant communities' point of views based on an incremental approach that leads immigrants and communities to develop basic, critical and finally political integration skills. The question remaining is: What is currently in place to incrementally move immigrants from basic, critical and political ISSL?

The discussion suggests that service delivery should keep in mind the developmental process of ISSL. As immigrants arrive, taking into consideration a variety of factors such as gender, past trauma, level of education, language, age and religion is crucial. To meet the ISSL continuum from basic, critical to political ISSL, immigrants should be taught to think about immigrant services offered to them and be able to provide their feedback bout available and missing services. In this case, immigrant services delivery becomes a strategic action more than simply providing services. It appears to be a vital "value added" achievement aiming to teach immigrants think critically as transformed agents. Unfortunately, the funding and service delivery models and political culture in place reinforce an "obedience mentality" among immigrants meaning "take it as it is or go away of it".

The discussion also indicates that there is a need for community organizations providing services to immigrants to be aware of the full sociopolitical context of ISS in order to identify best ISSL strategies. As well, immigrants should be aware of the socioeconomic and political context they live in to be able to understand the implications of the social structure on their integration in their host countries. In addition, immigrants should be provided space to voice their concerns, advocate for new directions and policies and suggest new solutions to the gaps in existing immigrant services. Any organization delivering services to immigrant communities should be able to respond adequately to the following question: what aspect of services already in place is actually helping immigrants gain a strong knowledge of existing 
services, critical thinking skills and political skills necessary to bring change to the course of policy development?

BISSL and CISSL are the foundations of PISSL. Therefore, as long as service providers and planners have the objective to promote the development of individual and ethnic community capacity to effectively use immigrant services, PISSL activities should focus on developing immigrant communities' consciousness about their capacity to improve their integration trajectories. Service evaluation should go further than traditional evaluation tools and start looking at initiatives that help foster immigrants' ISSL. The question "what and how do immigrant service providers have been able to do in promoting immigrants' critical thinking about available services should lead the evaluation of ISS. On a policy level, immigrant communities which are not capable to effectively voice their concerns about ISS should be interpreted as an indication of ineffective ISS planning and delivery by immigrant service providers.

The discussion allows concluding that looking at ISS through the lens of literacy provides the means to reflect on and interpret ISS access, use and related political mobilization issues in light of cultural, historical, political and social perspectives. In fact, like any other skills development, ISSL is not a neutral skill, but expands in relation to the socio-political environment in which individual and communities live. Therefore, the immigrant community size, economic power and overall social context will influence immigrants ISSL.

\section{References}

Audunson, R., \& Nordlie, R. (2003). Information literacy: the case or non-case of Norway? Library Review, 52(7), 319-325. http://dx.doi.org/10.1108/00242530310487416

Boekhorst, A. K. (2003). Becoming information literate in the Netherlands. Library Review, 52(7), 298-309. http://dx.doi.org/10.1108/00242530310487399

Canadian Council of Refugees. (1998). Best Settlement Practices: Settlement Services for Refugees and Immigrants in Canada.

COSTI. (2001). Settlement in the workplace. The settlement needs of employed newcomers, an exploratory study. [Online] Available: http://atwork.settlement.org/downloads/Settlement_in_the_Workplace.pdf

Dechief, D. (2006). "Recent Immigrants as an "Alternate Civic Core": Providing Internet Services, gaining "Canadian Experiences". Thesis (M.A.) Concordia University.

De Jong, G. F., Chamratrithirong, A., \& Tran, Q. G. (2002). For better, for worse: Life satisfaction consequences of migration. International Migration Review, 36(3), 838-63. http://dx.doi.org/10.1111/j.1747-7379.2002.tb00106.x

Delors, J., et al. (1996). Learning: the treasure within. Report to UNESCO of the International Commission on Education for the Twenty first Century. Paris: UNESCO.

Freire, P. (2000). Pedagogy of the Oppressed. New York, Continuum. 
Fisher, K. E., Durrance, J. C., \& Hinton, M. B. (2004). Information grounds and the use of need-based services by immigrants in Queens, New York: A Context-Based, Outcome Evaluation Approach. Journal of the American Society for Information Science and Technology, 55(8), 754-766. http://dx.doi.org/10.1002/asi.20019

Liu, M. (1995). Ethnicity and information-seeking. Reference Librarian, 49/50, 123-124. http://dx.doi.org/10.1300/J120v23n49_09

Martin, M. E. (2007). Introduction to Human Services: Through the Eyes of Practice Settings. New York: Earson/Allyn \& Bacon. MP.

Mehra, B., \& Papajohn, D. (2007). Glocal patterns of communication-Information convergences in Internet use: Cross cultural behaviour of international teaching assistants in a culturally alien information environment. International Information \& Library Review, 39, 12-30. http://dx.doi.org/10.1016/j.iilr.2007.01.001

Nutbeam, D. (2000). Health literacy as a public health goal: a challenge for contemporary health education and communication strategies into the 21st century. Health Promotion International, 15(3), 259-267. http://dx.doi.org/10.1093/heapro/15.3.259

Perry, K. (2012). What is Literacy? -A critical overview of sociocultural perspectives. Journal of Language and Literacy Education, 8(1), 50-71. [Online] Available: http://jolle.coe.uga.edu/wp-content/uploads/2012/06/What-is-Literacy_KPerry.pdf

Pettigrew, K. E., Fidel, R., \& Bruce, H. (2001). Conceptual frameworks in information behavior. In M. E. Williams (Ed.), Annual Review of Information Science and Technology, 35, 43-78. Medford, NJ: Information Today.

Saddeiqa, H. B. (1998). The Role of Immigrant Serving Organizations in the Canadian Welfare State: A Case Study. University of Toronto.

Satistics Canada. (2005). Learning a living: First results of the Adult Literacy and Life Skills Survey.

http://www.statcan.gc.ca/pub/89-603-x/2005001/pdf/4200878-eng.pdf

Statistics Canada, \& OECD. (2011). Literacy for Life: Further Results from the Adult Literacy and Life Skills Survey. Ottawa and Paris: Statistics Canada and OECD.

Silvio, D. H. (2006). The information needs and information seeking behavior of immigrant southern Sudanese youth in the city of London, Ontario: An exploratory study. Library Review, 55(4), 259-266. http://dx.doi.org/10.1108/00242530610660807

Sørensen, K., Van den Broucke, S., Fullam, J., Doyle, G., Pelikan, J., Slonska, Z., \& Brand, H. (2012). Health literacy and public health: a systematic review and integration of definitions and models. BMC Public Health, 12(80). http://dx.doi.org/10.1186/1471-2458-12-80

UNESCO. (1965). World Congress of Ministers of Education on the Eradication of Illiteracy: Statistics of illiteracy.

[Online] Available: 


\section{Macrothink}

http://unesdoc.unesco.org/images/0014/001481/148160eb.pdf

\section{Copyright Disclaimer}

Copyright reserved by the author(s).

This article is an open-access article distributed under the terms and conditions of the Creative Commons Attribution license (http://creativecommons.org/licenses/by/3.0/). 